\title{
LA APLICACIÓN DEL DERECHO CIVIL EN EL DERECHO DEL TRABAJO
}

\author{
Gabriela Lanata FuenZalida* \\ Universidad de Concepción
}

\begin{abstract}
RESUMEN: El presente estudio pretende determinar las relaciones existentes entre el Derecho Civil y el Derecho del Trabajo chilenos, en su regulación positiva. Busca detectar los alcances de la constante remisión del segundo al primero y su relación con la pretendida autonomía que aquel ha enunciado, con el fin de dilucidar si ello obedece a una real necesidad o, por el contrario, a un exagerado intento de socializar una realidad eminentemente jurídica. El punto de partida de la investigación realizada lo constituye la idea que la remisión efectuada desde el Derecho del Trabajo a instituciones o aspectos del Derecho Civil no le resta autonomía, y ello no obsta a que la aplicación de las normas contractuales civiles constituya un real aporte al logro de la protección del trabajador.
\end{abstract}

Palabras clave: Derecho del Trabajo, Derecho Civil, autonomía, remisión, protección, trabajador.

\begin{abstract}
This study aims to determine the relationship between civil law and Chilean labor law, in its positive regulation. It searchs for detecting the extent of the constant referral from second to first and its relation to the alleged autonomy has stated that, in order to ascertain whether this is due to the real necessity or, conversely, to an exaggerated attempt to socialize a reality that is eminently legal. The starting point of the investigation it is the idea that the referral from labor law to institutions or aspects of civil law does not reduce autonomy, and this does not prevent the application of civil contractual rules constitutes a real contribution the achievement of worker protection.
\end{abstract}

Key words: labor law, civil law, autonomy, remission, protection, worker.

\section{PRESENTACIÓN DEL PROBLEMA}

El Derecho del Trabajo constituye, históricamente, la respuesta a la insuficiencia del Derecho Civil para satisfacer las necesidades de una relación jurídica en las cuales las partes no están en un pie de igualdad.

La afirmación indicada ha llevado a que se haya intentado por quienes estudian el derecho laboral una incesante búsqueda de elementos que demuestren la absoluta independencia entre ambas disciplinas, con la idea de que sólo así se logrará la efectiva protección de quien se presenta como la parte débil de una relación contractual, la cual, sin embargo, se estudia y analiza a la luz de los propios principios tradicionales que inspiran su regulación civil. Frente a esta posición y debido a la realidad de la regulación de las relaciones laborales, se ha intentado explicar la necesidad de aplicar el Derecho Civil a través de la enunciación y desarrollo de distintas teorías, sosteniendo la existencia de una autonomía solo relativa; resaltando la llamada particularidad y especialidad del derecho laboral, que prima respecto del carácter de derecho común de la normativa civil, pero aceptando la aplicación supletoria de éste respecto de aquél y llegando, incluso, a plantearse el regreso al Derecho Civil como una necesidad de mejor protección a los trabajadores.

* Abogada. Profesora de Derecho del Trabajo, Facultad de Ciencias Jurídicas y Sociales, Universidad de Concepción. 
Gabriela Lanata Fuenzalida/La aplicación del Derecho Civil en el Derecho del Trabajo

Partiendo de la premisa básica que el Derecho del Trabajo no agota en su regulación positiva todos los aspectos inherentes a las relaciones que pretende regular, el problema central de este estudio es determinar si los planteamientos consagrados en el Derecho Civil constituyen la respuesta a todas las interrogantes que la aplicación del Derecho del Trabajo plantea o si, por el contrario, se hace necesaria la formulación de una teoría general que sirva de base a su elaboración o, aún, si la utilización de conceptos regulados por el Derecho Civil obedece solamente a que se trata de instituciones generales de derecho y que no pueden considerarse exclusivas del Derecho Civil.

Muchos son los aspectos que no tienen respuesta directa en el derecho positivo y que nuestros legisladores han dado por establecidos sin mayor preocupación sobre las consecuencias que su aplicación acarrea. Ha sido el propio derecho positivo laboral el que ha efectuado una remisión poco precisa a instituciones desarrolladas por el Derecho Civil, sin explicitar ni prever las consecuencias que ello puede conllevar. Nuestra realidad nos demuestra que, incluso, ello ha constituido un retroceso en la protección que, de alguna forma, le había conferido a los trabajadores la jurisprudencia judicial, según se dirá más adelante.

Normalmente, se tiende a señalar que la labor enunciada es cumplida a satisfacción por los principios propios de la disciplina. Sin embargo, se ha detectado en la jurisprudencia nacional y también en la aplicación legislativa de los mismos, un escaso dominio de los alcances conceptuales que presentan, incluso a la hora de catalogarlos como tal, sin que exista coincidencia o acuerdo ni siquiera en cuanto a cuáles son estos principios.

En la actualidad, se puede sostener que ya no se está frente a un derecho cuya esencial característica es estar dotado de normas inderogables relativamente, ni tampoco de una disciplina compuesta de instituciones propias diferentes a las demás, como ocurre con los efectos normativo y el indudable carácter de fuente del derecho de los instrumentos colectivos del trabajo, sino de un derecho de carácter social, según se tendrá ocasión de demostrar. Esta esencial característica y su correcto alcance debe ser determinante a la hora de buscar respuestas frente al problema de los vacíos de la ley laboral, pues debe llevar a determinar no solo las normas aplicables sino los alcances de las mismas. No puede prescindirse de los aspectos axiológicos a la hora de buscar soluciones. Es precisamente el cumplimiento de esta afirmación lo que determinará el grado de autonomía del derecho laboral. Su peculiar carácter social debe ser considerado al momento de buscar soluciones. Sin embargo, el tema ha sido enfocado como un asunto netamente de aplicación supletoria de ciertas normas, discutiéndose si se atenta o no a su independencia o autonomía y no si la solución proporcionada resulta coincidente con las características intrínsecas y esenciales del Derecho del Trabajo.

Desde un enfoque positivista, el problema pasa por determinar hasta qué grado se ha dado la independencia que han buscado los diversos ordenamientos jurídicos y si se está realmente frente a una autonomía entre ambas disciplinas o, por el contrario, se trata de la creación de un conjunto de normas dotadas de importantísimas particularidades, pero que han requerido y seguirán requiriendo de la constante remisión al Derecho Civil, en atención de la ausencia del desarrollo de una Teoría General del Derecho del Trabajo y a la evidente idolatría del carácter contractual en que, seguimos entendiendo, se basa la relación laboral, lo que trae como consecuencia necesaria que el Derecho Civil pueda constituirse en respuesta eficaz frente a aquellas necesidades jurídicas no resueltas directamente por la normativa laboral.

Constantemente, el propio derecho positivo laboral se está remitiendo, ya sea de manera directa o implícitamente, a instituciones no desarrolladas en sus normas, en temas tan trascendentes como formación de consentimiento, vicios del mismo y capacidad; modalidades contractuales; régimen de responsabilidad, en que destaca la aplicación de nociones de incumplimiento 
contractual, perjuicios y su indemnización, daño, solidaridad, por mencionar algunos aspectos. Sin embargo, la aplicación de cada una de estas instituciones implica serias consecuencias jurídicas que llevan muchas veces a soluciones concretas que no respetan el carácter social del Derecho del Trabajo o que, simplemente, no hacen efectivo el principio protector del trabajador, como su característica esencial.

No puede dejar señalarse que debe existir una regla básica que domina los diversos derechos subjetivos, que puede considerarse "derecho en general"1, que lleva a concluir que cada relación jurídica descansa en una regla determinada, pero se halla debajo de una institución jurídica que es su tipo y que la domina. Todas las instituciones jurídicas están ligadas en un sistema, de manera tal que cada cuestión concreta se diferencia en la dimensión en que se desarrolla, pero no existe diferencia en su esencia. Es decir, las instituciones, esencialmente, pertenecen al Derecho en general, y su aplicación práctica se determina por la dimensión en que se produzcan.

\section{INDEPENDENCIA, ESPECIALIDAD Y PARTICULARISMO DEL DERECHO DEL TRABAJO}

Las relaciones que mantiene el Derecho del Trabajo con el Derecho Civil no ha sido un tema estudiado de manera orgánica, como tampoco las razones y consecuencias de su separación, aun cuando la mayor parte de los tratadistas reconocen y se refieren a los orígenes del primero en relación al segundo. La convicción de que los códigos civiles no contenían una respuesta apropiada a las cuestiones que planteaba el trabajo humano y las relaciones que generaba, se fue gestando desde fines del siglo XIX, y al amparo de innovaciones legislativas, poco o nada ortodoxas, alentó los esfuerzos dirigidos a la construcción de una doctrina jurídica sustitutiva de la tradicional ${ }^{2}$. Asimismo, se pensó a principios del siglo XX que los códigos civiles, inspirados en filosofías individualistas y en un liberalismo económico, no daban respuestas a las necesidades del industrialismo moderno ${ }^{3}$.

La doctrina tradicional y precursora en su época insistió en que el Derecho del Trabajo nació frente a la insuficiencia de las normas contractuales civiles para dar respuesta a una relación contractual en que las partes no se presentaban en igualdad de condiciones ${ }^{4}$. Deveali sostuvo que la aparición de la disciplina como rama diferenciada del Derecho Civil se debió principalmente al desarrollo de la industria manufacturera como consecuencia del llamado "maquinismo", dictándose normas con el fin de regular la nueva realidad social que se generaba, pues los códigos civiles de la mayoría de los países se limitaban a regular la locación de servicios y de obra de acuerdo con los principios del derecho romano a semejanza de otros contratos, atribuyendo así prevalencia a la voluntad de los contratantes. La doctrina se esforzó en enunciar las diferencias entre ambas formas contractuales 5 .

La autonomía de la voluntad y la libertad de contratación constituyeron paradigmas que no daban respuesta a las necesidades jurídicas de las nuevas contrataciones, llegando a sostenerse

\footnotetext{
Savigny, Federico Carlos. "Los Fundamentos de la Ciencia Jurídica", en: Instituto Argentino de filosofía jurídicA y social. La ciencia del Derecho. Buenos Aires, Argentina: Editorial Losada, 1949, p. 31.

2 Barbagelata, Héctor Hugo. El Particularismo del Derecho del Trabajo. Montevideo, Uruguay: Fondo de Cultura Universitaria, 1995, p. 9.

3 Palacios, Alfredo. El Nuevo Derecho. -3ºd.-. Buenos Aires, Argentina: Claridad, 1919, p. 63.

4 Deveali, Mario. Tratado de Derecho del Trabajo. Tomo I. Buenos Aires, Argentina: La Ley, 1964, p. 6.

5 De Ferrari, Francisco. Derecho del Trabajo. Tomo I. Buenos Aires, Argentina: Depalma, 1977, p. 418 y ss.
} 
Gabriela Lanata Fuenzalida/La aplicación del Derecho Civil en el Derecho del Trabajo

la ausencia de voluntad del trabajador cuando celebra un contrato de trabajo, ya que actúa bajo el apremio de la necesidad económica, estableciéndose, entonces, normas y fijándose condiciones mínimas inderogables para las partes, etapa que se conoce como una fase transitoria en la evolución de lo que hoy se considera Derecho del Trabajo ${ }^{6}$. El contrato de trabajo debía resultar del libre acuerdo de voluntades, pero en la realidad era el patrono quien fijaba las condiciones de trabajo. A medida que pasaba el tiempo se hizo más palpable el divorcio entre la teoría y la realidad; no existía contrato escrito, lo que permitía a los patronos ponerle término a su entera discreción o modificar las condiciones de trabajo a su voluntad. Solo con posterioridad a las dos guerras mundiales se muestra como aceptable el criterio de humanización del tratamiento de los obreros. El Derecho del Trabajo adquirió existencia como un estatuto destinado a cubrir las necesidades y aspiraciones de los trabajadores, cuando la clase trabajadora conquistó la libertad y el derecho a la asociación profesional. Pero a los anteriores factores de índole social y económico se agrega otro de gran importancia en nuestro estudio, de naturaleza jurídica, cual es, la crítica a la teoría del contrato y a la doctrina de la autonomía de la voluntad o, si se prefiere, es la prueba de la falsedad de estas ideas en relación con el contrato de trabajo, demostración que abre el campo a la legislación social ${ }^{7}$. Esta realidad ha hecho sostener a algunos que el Derecho Civil es el derecho madre del cual se han ido disgregando las otras ramas del ordenamiento privado, entre las cuales cuentan al Derecho del Trabajo, llegando a atribuirle el carácter de supletorio de éste ${ }^{8}$, posición no de menor importancia en consideración a las reflexiones que se expondrán.

Las explicaciones en torno a esta separación varían en algunos matices. Lo ya expresado no debe entenderse como la exaltación de un derecho especial en el sentido de constituir un derecho de excepción, que sustrae a los asalariados del campo de aplicación de las normas generales de derecho. Se trata, sí, de un derecho especial, pero porque se refiere a determinada categoría de personas y por derogar el derecho común en cuanto aquel contiene principios y normas diferentes de los principios generales que informan al derecho 9 .

Otros justifican la diferencia entre ambas disciplinas en sus instituciones propias, diferentes a las de derecho común, que han constituido el verdadero embrión del que califican como nuevo derecho, que viene a constituir el núcleo del mismo, partiendo de la aplicación de la locación de servicios y de obra, a las cuales se limita el Derecho Civil, pasando por una segunda fase de predominio de lo económico a través del desarrollo del derecho colectivo del trabajo, hasta una tercera fase llamada de derecho social ${ }^{10}$ constituyendo, simplemente, aquella primera fase, la dictación de normas jurídicas dotadas de la característica de la inderogabilidad.

Son diversas las posturas que se han adoptado frente a la innegable necesidad de aplicación de preceptos civiles en distintas etapas del desarrollo de las relaciones laborales, destacándose aquellas que respaldan la existencia de una autonomía relativa en que se reconoce que el Derecho del Trabajo no es un derecho aislado ni de excepción, sino especial. Es decir, se sustenta esta autonomía relativa en esa especialidad del derecho laboral, aceptándose la existencia de normas

\footnotetext{
Deveali, Mario, Tratado.... (n. 3), p. 7.

De la Cueva, Mario. Derecho Mexicano del Trabajo. Tomo I. -10ed.-. D.F., México: Editorial Porrúa, 1967, p. 28.

8 Rodríguez Mancini, Jorge, (Director); Ackerman Mario (Colaborador). Curso de Derecho del Trabajo y de la Seguridad Social. Buenos Aires, Argentina: Astrea, 1993, p. 32 y ss.

9 Gaete Berríos, Alfredo. Derecho del Trabajo. Santiago, Chile: Editorial Universitaria S.A., 1956, p. 5 y ss.

10 Deveali, Mario. El derecho del trabajo: en su aplicación y sus tendencias. Buenos Aires, Argentina: Astrea, 1983, p. 34.
} 
y principios propios, pero que carece de autosuficiencia normativa, lo que permite propugnar la relatividad de su independencia respecto del Derecho Civil ${ }^{11}$.

Se han enunciado, asimismo, medios técnicos jurídicos utilizados para lograr que los principios aplicables a esta rama jurídica se realicen en forma práctica en los hechos propios de la relación laboral. En caso contrario, sostiene Mancini ${ }^{12}$, tales principios implicarían exclusivamente una mera declaración teórica, sin regular la conducta imperante en dicha realidad fáctica. Estos instrumentos, agrega el autor, actúan como herramientas para asegurar el principio de la libertad en la realidad de los hechos, que se produce en la vinculación entre trabajador y empleador. El Derecho del Trabajo adoptó determinadas herramientas -o instrumentos- que se han ido perfeccionando, buscando evitar el abuso del más fuerte, pero también del más débil, ya que ello podría producirse cuando la protección del indefenso va más allá de lo necesario, por ejemplo, al pretender que se aseguren condiciones que tampoco serían justas. Estos instrumentos están constituidos por instituciones tales como la limitación de la autonomía de la voluntad; la noción de orden público laboral ${ }^{13}$; sustitución automática de las cláusulas nulas por la norma violada; aquellos destinados a preservar la vigencia del contrato de trabajo; la irrenunciabilidad de los derechos laborales; las limitaciones de las facultades jerárquicas del empleador ${ }^{14}$; el fortalecimiento del grupo, como condición de igualdad para los trabajadores; el control administrativo, que cada vez se acentúa de mayor forma en su rol fiscalizador y claramente preventivo de los problemas laborales.

Las características propias de la realidad que corresponde al marco específico del Derecho del Trabajo, ha hecho que éste adopte algunas reglas fundamentales propias, distintas de las que rigen en otras ramas sobre todo en la común, a fin de facilitar soluciones de justicia en una relación en que las partes no gozan de igual capacidad para negociar el trato. La introducción dentro del panorama jurídico de ciertas normas ajustadas a principios distintos de los que regían en las otras relaciones contractuales, ha hecho que su normativa se amplíe a tal punto que, en la actualidad, constituye un aspecto esencial en los ordenamientos jurídicos.

Las consecuencias de lo expuesto no siempre se han establecido con claridad y en más de una oportunidad pueden generar excesos que conspiren contra la finalidad perseguida: que la igualdad de las partes desiguales se desenvuelva dentro de un marco de respeto hacia los derechos de cada uno de ellos. Lo fundamental es que los derechos no tienen como única causa al convenio que dio origen a la relación, sino que también emanan en la naturaleza de esta última y en la vocación y dignidad del hombre que se vincula a otro a través de ésta.

Como indica Vásquez Vialard ${ }^{15}$ la circunstancia de que el Derecho del Trabajo se rija, por lo menos parcialmente, por principios propios distintos de los del Derecho Civil, le otorga cierta peculiaridad. Lo importante, dice, es determinar el ámbito de esa independencia y se pregunta, ¿Es total o parcial? ¿Se trata de un derecho distinto o de uno que tiene especiales características

\footnotetext{
11 VÁsquez, Gabriela Alejandra. El regreso al Derecho Civil para la protección del trabajador. Buenos Aires, Argentina: Educa, Editorial de la Universidad Católica Argentina, 2004, p. 29.

12 Rodríguez Mancini, Jorge, (Director); Ackerman Mario (Colaborador). Curso de Derecho... (n. 8), p. 62 y ss.

13 Mancini sostiene que el orden público laboral es "una limitación de la autonomía de la voluntad individual, dispuesta por la ley, con miras al interés general", y agrega que presenta un carácter unilateral, al estar destinado a proteger al trabajador subordinado, como parte débil de la relación laboral. Rodríguez Mancini, Jorge. La Negociación Colectiva. Buenos Aires, Argentina: Astrea, 1990, pp. 25 y 28.

14 Santos Fernández, María Dolores. El contrato de trabajo como límite al poder del empresario. Albacete, España: Bomarzo, 2005, p. 55 y ss.

15 Vásquez Vialard, Antonio. Tratado de Derecho del Trabajo. Tomo II. Buenos Aires, Argentina: Astrea, 1982, p. 90 y ss.
} 
Gabriela Lanata Fuenzalida/La aplicación del Derecho Civil en el Derecho del Trabajo

impuestas por principios propios que en la medida en que éstos no son desvirtuados, admiten la aplicación subsidiaria de los de derecho común?

El autor critica la utilización de la expresión "independencia" o "autonomía" para referirse al tema en estudio proponiendo como más adecuado el término "particularismo" que se refiere a diversos aspectos, pero se destaca especialmente uno, que es el que lo relaciona con una distinción de carácter científica, cual es, que disciplina una realidad social, suficientemente vasta para merecer un estudio adecuado y particular, contando para ello con principios generales propios, homogéneos y distintos de los de derecho común ${ }^{16}$.

En concordancia con las afirmaciones de Vásquez Vialard la doctrina, aun cuando de forma más bien enunciativa, ha estudiado las relaciones que existen entre ambas disciplinas, en posiciones que van desde la aplicación supletoria del Derecho Civil en el Derecho del Trabajo ${ }^{17}$ hasta el retorno al Derecho Civil como una forma de protección al trabajador ${ }^{18}$.

Se ha planteado, igualmente, el reconocimiento de la esencia unitaria del Derecho y de la exigencia del tratamiento jurídico de los problemas laborales. Resalta la necesidad de no olvidar, al buscarles solución, los aspectos sociológicos, pues ello sería privar a aquellos de su sustancial vida propia. El estudio del problema social debe ser un presupuesto para comprobar si la norma jurídica vigente es la idónea y un horizonte en vista de su posible modificación, pero al examinar la norma no puede olvidarse ni su positividad actual ni la necesidad de interpretarla y aplicarla dentro del mundo de lo axiológico, permanente en cuanto sea vigente, y no de lo fenomenológico, por esencia cambiante ${ }^{19}$.

Dentro de este panorama es factible preguntarse si la aplicación supletoria del derecho común es adecuada al fenómeno laboral o si, por el contrario, es mejor reducir al máximo tal supletoriedad limitándola a la remisión expresa del derecho laboral, atendida la realidad sociológica que rodea el desenvolvimiento de los problemas laborales. No puede obviarse la realidad evidente de la ruptura de los nexos causales existentes entre el objeto y el contenido del Derecho del Trabajo, que han llevado a que los cambios normativos y doctrinarios no sólo no sean una consecuencia inmediata sino, tal vez, ni siquiera mediata, de las novedades producidas en el campo de las relaciones de trabajo.

\section{RELACIONES DEL DERECHO DEL TRABAJO CON EL DERECHO CIVIL}

Debe recordarse que, históricamente, la explicación de la existencia de una relación de trabajo fue considerada como el resultado de un contrato, semejante a los restantes contratos del Derecho Civil. Esta idea encontraba fuerte apoyo en la teoría de las fuentes de las obligaciones, en que se esgrimía como únicas posibles a la ley o a los contratos, por lo tanto, las que se detectaban entre trabajadores y empleadores sólo podían emanar de este último. Los esfuerzos de la doctrina se dirigieron, entonces, a determinar frente a qué tipo de contrato se encontraban, ello siempre dentro de una lógica civilística. Hubo quienes lo consideraron como una forma especial de arrendamiento de servicios, posición que fue fervientemente defendida por Marcel Planiol. El tratadista

\footnotetext{
Ibid., p. 92.

Mangarelli, Cristina. Aplicación supletoria del Derecho Civil en el Derecho del Trabajo. Doctrina y Jurisprudencia. Montevideo, Uruguay: Fundación de Cultura Universitaria, 2000.

18 Vásquez Vialard, Antonio, op. cit. (n. 15).

19 Bayón Chacón, G. y Pérez Botija, E. Manual de Derecho del Trabajo. Vol. 1. Madrid, España: Marcial Pons, 1995, p. 165.
} 
alemán Philipp Lotmar criticó esta teoría sosteniendo que la energía de trabajo del obrero no formaba parte de su patrimonio y, por lo tanto, no podía ser objeto de un contrato. Es así como el trabajo permanece unido íntimamente a la persona que desempeña el servicio. El tratadista Francesco Carnelutti se esforzó en demostrar que el contrato de trabajo podía ser clasificado como un contrato de compraventa. Esta posición se levantaba en contra de aquella que propugnaba que el contrato de trabajo era un arrendamiento, pues lo que el trabajador aportaba era en definitiva su energía, la que a diferencia de lo que ocurre con la cosa arrendada, no podía ser devuelta a su dueño. Se consideraba la energía humana como una cosa, susceptible de ser vendida.

No faltó la referencia al contrato de sociedad, posición que fue defendida por el tratadista Chatelain ${ }^{20}$, partiendo de la noción de empresa, sostuvo que en el contrato de trabajo se dan dos elementos: obra común de varias personas, cada una de las cuales aporta algo, y división en común de alguna cosa, elementos que podían ser identificados con el aporte de trabajo y derecho a retribución que se daban en el contrato de trabajo.

Ninguna de estas ideas fueron suficientes para explicar la naturaleza jurídica de la nueva figura, tal vez como resultado de la noción incipiente que el Derecho del Trabajo difiere esencialmente del Derecho Civil, por sus fundamentos y sus propósitos:

"El Derecho del Trabajo no es un derecho para regular la conducta de los hombres en relación con las cosas, sino que es un derecho para el hombre; sus preceptos e instituciones tienen como finalidad inmediata, no solamente proteger la energía humana de trabajo, sino, más bien, asegurar a cada hombre una posición social adecuada, esto es, constituye no reglas para regular la compraventa o el arrendamiento de la fuerza de trabajo, sino un estatuto personal que procura elevar al hombre a una existencia digna. Por eso es que "la semejanza en las instituciones no puede resolver los problemas, porque la esencia de las mismas instituciones es distinta"21.

Como puede observarse, ya se aparece la incipiente idea de que, en algún momento, el enfoque de los problemas puntuales que emanan del contrato de trabajo no encontrarán respuesta adecuada en la normativa civil, obligando al juez a exagerar la aplicación de sus normas o a realizar una aplicación diferente, sustentándose en la existencia de principios propios del Derecho del Trabajo, particularmente aquel que propugna la protección de la parte débil de la relación laboral, pero apartándose, sea por una razón u otra de la clásica normativa que entrega el Código Civil.

La relación existente no es una cuestión en que exista unanimidad entre los autores, aun entre aquellos que plantean derechamente su separación. Y agregando a la posición ya expuesta de Vásquez Vialard, otros como Deveali, sostienen el concepto de la autonomía relativa ${ }^{22}$, y como Plá, el particularismo (o especialidad) de este derecho ${ }^{23}$.

Así, el tema de las relaciones de ambas disciplinas ha despertado más de alguna inquietud, siendo abordado desde diferentes puntos de vista, ya sea para intentar plasmar sus opiniones en el sentido de defender a ultranza su autonomía, como una forma de preservar su existencia o expli-

\footnotetext{
20 Chatelain, Emilio. El Contrato de Trabajo. Traducción de Adolfo Posada. Madrid, España: Imprenta de la Revista de Legislación, 1903.

21 De la Cueva, Mario, op. cit. (n. 7), p. 453.

22 Deveali, Mario. Lineamientos de Derecho del Trabajo. Buenos Aires, Argentina: Tea, 1948, p.14.

23 Plá Rodríguez, Américo. Los principios del Derecho del Trabajo. -2² Edición-. Buenos Aires, Argentina: Editorial Depalma, 1998, p. 27.
} 
Gabriela Lanata Fuenzalida/La aplicación del Derecho Civil en el Derecho del Trabajo

car de manera satisfactoria la innegable aplicación de normas y, por qué no decirlo, de principios contractuales civiles.

Algunos autores han tratado el tema como la simple necesidad de llenar los vacíos de la legislación laboral, es decir, atribuyéndole al Derecho Civil un carácter derechamente supletorio del laboral ${ }^{24}$, llegando, incluso, como lo hace Vásquez, a plantear el regreso al Derecho Civil como una forma de hacer efectiva la protección debida al trabajador ${ }^{25}$. No parece que hoy perduren dudas en el sentido de que el Derecho del Trabajo, pese a estar dotado de normas y principios propios, sostiene la autora, carece de autosuficiencia normativa y que, por ello, su naturaleza especial no permite sino propugnar la relatividad de su independencia respecto del Derecho Civil.

La situación no es del todo pacífica, pues si bien se ha reconocido la tendencia actual de aceptar la aplicación de conceptos generales extraídos del Derecho Civil aun cuando no exista vacío en el derecho laboral, se rechaza esta posibilidad porque la norma especial deroga la general y porque, además, ello pone en crisis la especialidad del Derecho del Trabajo, arriesgando la vigencia de soluciones jurídicas particulares que la disciplina ha adoptado ${ }^{26}$.

Otros han enfocado derechamente el contrato de trabajo como un negocio jurídico, describiendo los elementos que lo caracterizan desde el prisma de un acuerdo de voluntades destinado a crear derechos y obligaciones entre las partes ${ }^{27}$, denunciando que no existe otra forma mejor de explicar su naturaleza jurídica ${ }^{28}$.

La autora uruguaya Cristina Mangarelli afirma que el Derecho del Trabajo, al ser un derecho especial, debe prevalecer por sobre las normas generales o comunes, pero reconoce que el sistema jurídico constituye un todo unitario, "por lo que las distintas ramas del derecho no se encuentran aisladas del resto del ordenamiento jurídico, sino en continua relación entre sí" 29 .

En el campo del derecho positivo chileno, en alguna época se tuvo que hacer uso a las normas del derecho común, pero fue la realidad social la que impulsó u obligó a la dictación de normas especiales que luego se transformaron en nuestro primer código del trabajo cuya vigencia hizo que se buscara una independencia lo más acentuada posible del Derecho Civil, pues se entendía como un importante logro social y un avance indudable en la realización de la justicia para la clase obrera. Cabe hacer presente que esta situación obedeció más bien a anhelos ideológicos que científicos jurídicos y el debate en este último aspecto no resultó una preocupación de consideración.

Sin embargo, y desde la perspectiva actual, no puede pensarse que en época alguna haya podido prescindirse de la aplicación de normas de Derecho Civil en materias laborales.

Los autores argentinos tampoco han propiciado la separación absoluta. Krotoschin, reconoce que el Derecho del Trabajo es un derecho especial para un solo sector social, aunque se trate de un sector sumamente importante, ya numéricamente. Pero advierte que este sector está vinculado a la sociedad entera, y el Derecho del Trabajo, por lo tanto, está incorporado necesariamente al ordenamiento jurídico general. Señala, además, que “...no es un derecho aislado sino que se ha desarrollado y sigue desarrollándose en estrecho contacto con otras ramas jurídicas” y agrega que

\footnotetext{
Mangarelli, Cristina, op. cit. (n. 17), p. 15.

25 Vásquez Vialard, Antonio, op. cit. (n. 15), p. 22.

26 Mangarelli, Cristina, op. cit. (n. 17), p. 109.

27 Arias Gilbert, Enrique. El negocio jurídico laboral. Buenos Aires, Argentina: Editorial LexisNexis, 2007, p. 30 y ss.

28 Hierrezuelo, Ricardo D. y Núnez, Pedro F. Responsabilidad Solidaria en el Derecho del Trabajo, Buenos Aires, Argentina: Hammurabi, 2008, p. 52.

29 Mangarelli, Cristina, op. cit. (n. 17), p. 15.
} 
"precisa ser completado por los conceptos y también por las consideraciones estimativas de otras partes del ordenamiento jurídico" 30 .

El eminente autor reconoció de manera expresa que al ser aplicado o interpretado el Derecho del Trabajo no podían descuidarse los fundamentos metodológicos válidos para la ciencia jurídica y ello, por ser parte del ordenamiento jurídico ${ }^{31}$.

De Buen reconoce la necesidad de recurrir a las reglas del derecho común, señalando que "por muy desarrollada que esté una disciplina especial, nunca podrá colmar la totalidad de los problemas de sus sujetos, de sus actos, y de sus normas, los que necesariamente estarán subordinados en última instancia a reglas del derecho común"32.

Un punto de trascendencia es determinar qué se entiende por derecho común frente al derecho laboral. No existe unanimidad entre los autores para considerar que el Derecho Civil es, en este sentido, el derecho común frente al Derecho del Trabajo, pero sí que su aplicación resulta necesaria frente a los vacíos que la ley laboral experimente, pudiendo eso sí, recurrirse a otras disciplinas cuando ello corresponda, como por ejemplo al derecho comercial, procesal o penal.

Siempre ha de tenerse en vista, eso sí, a la hora de recurrir a la integración con otras disciplinas, el respeto a los principios propios del Derecho del Trabajo, sin olvidar que, como ya se indicó, éste nace frente a la falta de respuesta de las otras disciplinas a los problemas que le son propios.

La doctrina chilena no ha estado ajena a estos planteamientos, sin embargo no ha sido un tema objeto de estudio directo. En la doctrina nacional, en 1936 Alfredo Gaete Berríos ${ }^{33}$, en su Memoria de Prueba para optar al Grado de Licenciado en Ciencias Jurídicas, trataba el tema como modificaciones introducidas al derecho Civil, por lo que ya en esa época llamó "derecho social", refiriéndolas a las materias de contratos y obligaciones. Además del innegable valor histórico que la obra presenta en el estudio de estas materias, cabe destacar que se trata del primer acercamiento efectuado en Chile a un problema que aparece, en la actualidad, como de la mayor preocupación.

Ya desde su título queda en evidencia lo peculiar de su presentación, considerando que lo que había nacido en Chile era un derecho social, que venía derechamente a modificar el Derecho Civil contractual existente entonces.

El profesor Francisco Walker sostiene la misma posición, defendiendo la autonomía del Derecho del Trabajo, pero sin negar la necesaria interrelación con las demás ramas del derecho. Así, ha escrito que “...presenta características propias que lo diferencian de las otras ramas del derecho, y le dan una individualidad perfectamente determinada”. Y entre las características que indica señala la de su autonomía, pero la esboza de la siguiente forma:

"Es autónomo y especial; su autonomía es la de una disciplina particularista dentro de la unidad orgánica del derecho; la especialidad no hace perder la visión del conjunto; como dice Víctor Duruy, "il faut etre universel au profit d'une espécialite" ("es preciso ser universal en beneficio de una especialidad"). La autonomía no significa independencia ni aislamiento; el derecho es un árbol frondoso y secular con raíces romanas, que se va renovando constantemente y cuyas ramas, todas nacidas de un tronco común, tienen un crecimiento desigual; entre tales ramas, la que hoy día se desarrolla con mayor vigor es la del Derecho del Trabajo, el derecho del porvenir.

\footnotetext{
30 Krotoschin, Ernesto. Tratado Práctico de Derecho del Trabajo. Tomo I. Buenos Aires, Argentina: Editorial Depalma, 1962, p. 8.

31 Krotoschin, Ernesto. Manual de Derecho del Trabajo. -4º Edición-. Buenos Aires, Argentina: Editorial Depalma, 1993 , p. 9.

32 De Buen L., L. Derecho del Trabajo. Tomo I. -10ª edición-. D.F., México: Editorial Porrúa, 1997, p. 117.

33 Gaete Berríos, Alfredo. Principales modificaciones que ha introducido el derecho social al derecho civil en materia de contratos y obligaciones. Santiago, Chile: Talleres Gráficos Gutenberg, 1936.
} 
Gabriela Lanata Fuenzalida/La aplicación del Derecho Civil en el Derecho del Trabajo

Si bien el Derecho del Trabajo comenzó tímidamente desprendiéndose del Derecho Civil, ahora posee una individualidad bien definida, y se diferencia de una manera substancial de las demás disciplinas jurídicas, aun cuando tenga con ellas muchos puntos comunes, fuertes vinculaciones y recíprocas penetraciones" 34 .

El mismo autor indica, al referirse al orden de aplicación de las fuentes formales del Derecho del Trabajo que, en primer lugar deben aplicarse las disposiciones especiales laborales y de previsión y luego las otras leyes que no sean del trabajo o las que sólo tienen un carácter supletorio para el efecto de faltar una ley propiamente laboral o previsional respecto de la misma materia ${ }^{35}$.

Según lo expuesto, no parecen persistir hoy dudas en el sentido de que el Derecho del Trabajo, pese a estar dotado de normas y principios propios, carece, a lo menos, de autosuficiencia normativa y que por ello su naturaleza especial ha llevado a propugnar la relatividad de su independencia respecto del Derecho Civil ${ }^{36}$.

En el año 1936 don Francisco Walker Linares, al informar la memoria de prueba de Alfredo Gaete Berríos, ya aludida indicó: "El profesor que suscribe está en absoluto acuerdo con el autor en cuanto éste afirma que el Derecho del Trabajo no es una simple rama del Derecho Civil, sino un Derecho con individualidad propia, sin rigideces ni formulismos, con características sui-géneris, y cuyas proyecciones son inmensas, siendo el Derecho del porvenir" ${ }^{37}$.

Gaete sostuvo que lo que denominó modificaciones al Derecho Civil “(...) tienden a restringir o, más bien dicho, a anular el principio de la autonomía de la voluntad, que tan funestos resultados ha tenido para las clases desposeídas de la fortuna, que se han visto obligadas a contratar sus servicios como único medio de subsistir, quienes quedaban entregadas por entero a la inexorable ley de la oferta y la demanda". Y concluyó, finalmente, que "El Derecho Social tiende a que reine la armonía y la felicidad entre los hombres. En una palabra, este Derecho pretende que las palabras del célebre pensador inglés Hobbes que dicen: "que el hombre para el hombre es un lobo", dejen de ser una realidad" 38 .

Pero la doctrina no se ha limitado solamente en calificar estas innovaciones como simples modificaciones al Derecho Civil, sino que ha planteado, derechamente, la autonomía del Derecho del Trabajo.

De Buen sostiene que analizar si una disciplina es o no autónoma se traduce a determinar si reúne las condiciones necesarias como para constituir lo que él denomina "un tercer escaño".

En cuanto a cuáles son estas condiciones puede advertirse alguna disparidad entre los autores. La tesis tradicional parece haber sido sostenida por Cabanellas, para quien la autonomía se presenta en cuatro direcciones: legislativa, científica, didáctica y jurisdiccional.

La autonomía legislativa radica en la existencia de su propio sistema normativo o de la existencia de sus propias fuentes. La autonomía científica, radica en la elaboración de doctrinas propias, independientes, que le confieren una fisonomía particular. La didáctica, por su parte, en

\footnotetext{
34 Walker Linares, Francisco. "Concepto, naturaleza y características del Derecho del Trabajo", en: Anales de la Facultad de Derecho. Tercera Época. Vol. III. Enero a Diciembre 1956. No 5. También en http://www.analesderecho.uchile.cl

35 Walker Linares, Francisco. Fuentes del Derecho del Trabajo y su jerarquía, en: Revista del Trabajo, Santiago, Chile, diciembre de 1951 , p. 43.

36 Vásquez Vialard, Antonio, op. cit. (n. 15), p. 32.

37 Walker Linares, Francisco, Francisco. Informe a la Memoria de Prueba para optar al grado de Licenciado en Ciencias Jurídicas y Sociales, en: GaEte Berríos, Alfredo, op. cit. (n. 33), p. 5.

38 Gaete Berríos, Alfredo, op. cit. (n. 33), p. 53.
} 
la existencia de cátedras propias destinadas a su enseñanza. Finalmente, la autonomía jurisdiccional deriva de la existencia de tribunales propios para la disciplina jurídica de que se trate.

Para De Buen ${ }^{39}$, en cambio la autonomía descansa sobre el fenómeno social a que responde. La disciplina será autónoma dada su trascendencia social, independientemente del texto formal en que estén contenidas sus reglas.

Sin perjuicio de la discusión teórica, resulta indudable que el Derecho del Trabajo reúne las condiciones para ser considerada una disciplina autónoma. La autonomía legislativa, aun cuando no parece ser éste un criterio decisivo, parece cumplirse, al existir un código especializado en la materia y normas complementarias también especiales. Las doctrinas y fundamentos propios, indudablemente son una realidad y determinan el fundamento mismo de su existencia, constituido especialmente sobre la base del principio protector y de las limitaciones a la autonomía de la voluntad, que le confieren una fisonomía propia indiscutible. La autonomía didáctica también es indiscutible, al no existir carrera universitaria que no la contemple en sus planes de estudios. Se complementas todas estas condiciones con la especialidad de los juzgados de letras del trabajo, constituidos exclusivamente para conocer cuestiones laborales.

Sin embargo y coincidiendo con De Buen en este aspecto, puede afirmarse, sin temor a equivocarse, que su autonomía está dada por la gran trascendencia del fenómeno social a que responde, constituido, en el decir de Palomeque ${ }^{40}$, en la necesidad del Estado de intervenir en las relaciones de producción, a través de la promulgación de normas protectoras de las condiciones de vida y de trabajo del proletariado, y limitadoras, por lo tanto de la voluntad del empresario en la fijación del contenido del contrato de trabajo. No es necesario extenderse en explicar que esta finalidad es también necesaria en la realidad chilena.

Establecida ya la autonomía del Derecho del Trabajo, resulta pertinente dejar en claro que ello no obsta a que requiera la utilización de instituciones que no le son propias. La explicación radica, en el decir de Mangarellii ${ }^{41}$, en que la autonomía de una rama del derecho no supone apartamiento total del ordenamiento jurídico. Durand y Jaussaud ${ }^{42}$, en 1947 sostuvieron que el particularismo del Derecho del Trabajo no supone la exclusión radical de los principios generales o de las categorías jurídicas del derecho común.

De Buen reconoce derechamente que de todas las disciplinas jurídicas, el derecho civil resulta ser el de mayor vinculación, pero agrega que es la disciplina de la que con mayor energía quieren alejarse. Sostiene el autor, posición que comparto, que el Derecho del Trabajo tiene una íntima relación con el Derecho Civil, al igual que con todas las demás disciplinas jurídicas, y tratándose precisamente de esta disciplina, debe recurrir a conceptos básicos relacionados con la teoría de las normas, de las personas, de los negocios jurídicos, de la propiedad, "siempre pensando, de manera primordial, en las actividades comunes a todos los hombres, pero en términos tales que, con las particularidades de cada especialidad, éstas puedan, a su vez, suplir con ellas sus propias insuficiencias" ${ }^{\prime 3}$. Concluye, el autor, reconociendo la vinculación entre ambas disciplinas.

\footnotetext{
39 De Buen L., L., op. cit. (n. 32), p. 110.

40 Palomeque López, Manuel Carlos y Álvarez de la Rosa, Manuel. Derecho del Trabajo. - $17^{\circ}$ Edición-. Madrid, España: Editorial Universitaria Ramón Areces, 2009, p.72.

41 Mangarelli, Cristina, op. cit. (n. 17), p. 15.

42 Durand Y Jaussaud. Traité de Droit du Travail. Tome Premier. París, Francia, 1947, p. 259. Citado por Ibid., p. 15.

43 De Buen L., L., op. cit. (n. 32), p. 114.
} 
Gabriela Lanata Fuenzalida/La aplicación del Derecho Civil en el Derecho del Trabajo

De la Cueva también reconoce y acepta esta vinculación, calificando al estatuto laboral como la regla general y el derecho civil y mercantil como las normas de excepción ${ }^{44}$.

Lyon-Caen acepta lisa y llanamente la que denomina la incesante penetración del Derecho Civil en el Derecho del Trabajo, aunque se aboca a la búsqueda de las razones de tal circunstancia ${ }^{45}$.

De aquí entonces, que se hable de la supletoriedad del Derecho Civil en el Derecho del Trabajo $^{46}$ y de la calidad especial de la disciplina, aceptando la aplicación del Derecho Civil como necesaria y complementaria de aquella, pero sin que ello implique negar su autonomía.

En concordancia con lo dicho, se trata de una disciplina que puede ser calificada de especial. De Buen apoya esta calificación, en tanto sus normas se dirigen a los sujetos no en tanto personas, sino en cuanto pertenecen a una determinada clase social: la de trabajadores o la de empleadores, preocupándose sólo de una parte de las relaciones jurídicas, esto es, de aquellas que derivan de prestaciones de servicios subordinados, sin que ello implique, de manera alguna, la negación de la supletoriedad del Derecho Civil, disciplina que debe ser considerada como el derecho común ${ }^{47}$.

Pérez Botija reconoció, asimismo, esta condición al aceptar que, técnicamente, los preceptos civiles tienen carácter subsidiario de los laborales. Agregó el autor que "Espiritualmente, deben procurar informar el sentido de las normas de trabajo, siempre que no perturben los propósitos tutelares y protectores de las mismas" ${ }^{48}$. Reconoció como necesarios ciertos conceptos propios del Derecho de Familia, tales como la noción de persona y la capacidad de obrar y también de contrato, referido específicamente a la relación individual, el que, según el autor:

"Debe contar con la libertad de movimientos que le asegura el derecho de obligaciones, conceptos que se encuentran firmemente condicionados por el principio de la irrenunciabilidad y por el principio pro operario o de protección, pero, en lo que este condicionamiento permita, la fecunda libertad de pactos deberá arrojar su haz proyector en el Derecho Laboral" ${ }^{39}$.

En similar sentido, se ha hablado de los particularismos del Derecho del Trabajo, características ya expuesta por Paul Durand ${ }^{50}$ y más tarde desarrollada por Barbagelata ${ }^{51}$, quien plantea que la cuestión de la autonomía analizada ya es una cuestión superada. La particularidad esencial se relaciona, para este autor, y de la cual derivan, en cierta forma, todas las demás, con el objeto de su protección y supone una nueva actitud ante las realidades del mundo del trabajo, un cambio en la forma de concebir la igualdad de las personas. Las demás particularidades pueden referirse a la subyacencia del conflicto en las relaciones laborales; la dimensión colectiva del conflicto laboral; el papel central de la negociación; las repercusiones en el plano de las fuentes del derecho; signifi-

44 De La Cueva, Mario. El Nuevo Derecho del Trabajo. D.F., México: Editorial Porrúa, 1993, p. 438.

45 Lyon-Caen, G. "Du role de Príncipes Généraux du Droit Civil en Droit du Travail", en Revue Trimestrielle de Droit Civil. $73^{\circ}$ Année, Avril-June, 1974, N², p. 235.

46 A modo de ejemplo, puede citarse la obra de Molero Manglado, Carlos. La Supletoriedad del Derecho Común en el Derecho del Trabajo. Madrid, España: Centro de Estudios Constitucionales, 1975 y la obra ya citada de Cristina Mangarelli.

47 De Buen L., L., op. cit. (n. 32), p. 109.

48 Pérez Botija, Eugenio. El Derecho del Trabajo. Concepto, Substantividad y Relaciones con las Restantes Disciplinas Jurídicas. Madrid, España: Editorial Revista de Derecho Privado, 1947, p. 224.

49 Ibid., pp. 224 y 225.

50 Durand, Paul. "Le Particularisme du Droit du Travail”, en: Revista Droit Social. París, Francia, 1945, p. 298 y ss.

51 Barbagelata, Héctor Hugo, op. cit. (n. 2), pp. 20-21. 
cación del tiempo social en el sistema normativo-laboral y la variedad y poderes de los operadores jurídicos.

Como se observa, la autonomía del Derecho del Trabajo resulta indiscutible, como también lo es su carácter especial, lo que no excluye la posibilidad, por cierto indispensable, de aplicación supletoria del Derecho Civil.

\section{4. ¿REGRESO AL DERECHO CIVIL?}

Hoy se ve una directa alusión al Derecho Civil, cada vez más acentuado en los textos legislativos lo que lleva a replantearse las fronteras de ambas disciplinas. Se hace forzoso recordar nuevamente los planteamientos de Gaete en su Memoria de Prueba, ya citada, quien hablaba derechamente de modificaciones introducidas por el derecho social al Derecho Civil. El informante profesor Luis Barriga Errázuriz, sostuvo que lo que se había pretendido con la referida memoria era dar a conocer "las reformas introducidas al derecho común por el Derecho del Trabajo en materia de obligaciones y contratos" 52 .

Transcurrido ya casi un siglo, es posible constatar que en la realidad chilena el problema planteado no tiene una respuesta clara, lo que demuestra la relevancia práctica de detenerse a buscar respuesta a un problema cuya vigencia nuestro legislador y, en muchas ocasiones, los actuales pronunciamientos de los tribunales de justicia han tendido a acentuar.

No obstante la preocupación que el tema ha despertado en la doctrina, no se han enfocado los resultados concretos de las referencias efectuadas por la propia legislación laboral a determinadas instituciones reguladas por el Derecho Civil ni tampoco su aplicación frente a vacíos de la anterior, constituyendo un tema que ha debido ser enfrentado por la jurisprudencia al resolver el caso concreto, pero sin que se haya desarrollado una teoría general al respecto.

Son muchos los aspectos que no han sido suficientemente tratados por la doctrina, especialmente las consecuencias de la aplicación de institutos cuya teoría se desarrolla en el Derecho Civil, pudiendo mencionarse aspectos tales como la aplicación de la solidaridad y en general, todo el régimen de responsabilidad civil; el derecho de daños y prescripción extintiva, por decir algunos, que no han encontrado una posición unánime ni en la doctrina ni en la jurisprudencia.

Especial mención merece el tema relativo al reconocimiento de los derechos fundamentales de los trabajadores dentro de la vida empresarial, cuyo respeto ha debido ser consagrado legislativamente para constatar la simple necesidad de su existencia. Los derechos fundamentales que el trabajador no pierde por celebrar un contrato de trabajo son un punto de necesaria referencia al estudiar las peculiaridades, autonomía, especialidad o particularismo del derecho laboral, aun cuando su reconocimiento legislativo no es más que eso: la constatación de nuestra inexplicable necesidad de ver consagrada cada institución, cada derecho, en un texto legislativo particular.

Pocos son, sin embargo, los que detectan causas finales que justifiquen la especialidad o autonomía del Derecho del Trabajo. Sus particularidades tienen que ver con una nueva actitud ante las realidades del mundo del trabajo, lo que descansa en un cambio en la forma de concebir la igualdad de las personas ${ }^{53}$.

En Chile, el derecho laboral positivo se encuentra contenido, básicamente, en un código especializado que data del año 1987, que ha debido ser objeto de importantes modificaciones que

$52 \quad$ Ibid., p. 7.

53 Ibid., p. 20. 
Gabriela Lanata Fuenzalida/La aplicación del Derecho Civil en el Derecho del Trabajo

han tendido a adecuarlo a las modernas tendencias y necesidades de una sociedad cambiante, aspecto formal que no ha sido suficiente para consagrar una absoluta independencia. En efecto, son numerosas las instituciones de Derecho Civil de las cuales ha requerido, ya sea por expresa remisión de sus normas efectuadas por la propia normativa laboral, ya sea por tratarse de institutos no regulados en ésta, pero sí en el Código Civil o, por último, por tratarse de vacíos o lagunas de aquélla.

Los tribunales de justicia, por su parte, aún los especializados en materias laborales, constantemente recurren a normas civiles en la resolución de las controversias, pudiendo concluirse que en la actualidad el Derecho del Trabajo no se basta a sí mismo, lo que no quiere significar que se esté negando su autonomía, sino reconociendo que no obstante tratarse de una disciplina especial, existen tópicos de carácter general no desarrollados en ella, y para cuya aplicación requiere de las normas civiles.

Si bien se discutió su naturaleza jurídica, se ha instaurado la idea de que no se trata de una disciplina que forme parte del derecho privado ni tampoco del derecho público, no obstante la gran influencia que ambos han tenido en su configuración.

Suele afirmarse que esta división encuentra su origen en el jurisconsulto Ulpiano y su valor resulta muy contradictorio. Mientras Radbruch ${ }^{54}$ sostuvo que son categorías o conceptos jurídicos apriorísticos, es decir, que preceden lógicamente a toda experiencia jurídica otros, como Duguit ${ }^{55}$ han sustentado la idea de unidad, al señalar que los actos de derecho público y de derecho privado se encuentran conformados por los mismos elementos y la diferencia solamente está en su sanción. No es la idea llegar a determinar la validez de esas corrientes, sino reconocer que su existencia ha determinado, en gran medida, el tratamiento jurídico-laboral del sector productivo en un momento dado, ya que no obstante las críticas que se han formulado, lo cierto es que esta clasificación se mantiene y es común que los juristas hablen de derecho público y de derecho privado como de valores entendidos, reconociendo el indudable valor didáctico que ella presenta. No obstante, se ha llegado a sostener que el Derecho del Trabajo es un tertium genus, distinto del Derecho Público y Privado, ya que se trata de un "derecho social".

El liberalismo, con su optimismo traducido en que el libre juego de las fuerzas naturales llevaría al más alto grado de desarrollo la actividad económica de los hombres, hizo que el Derecho Privado sólo pudiera considerar los fenómenos de la producción y distribución como relaciones entre dos personas, cuyos intereses habían de nivelar de acuerdo con los principios de la justicia conmutativa, es decir, dar a cada uno lo suyo; por diversas razones, el Estado se vio forzado a regular todos los aspectos de la vida económica, dando origen a lo que se conoce como derecho económico, entendido como el derecho que regula la economía organizada y que implicó que el Estado ya no dejara actuar a las fuerzas económicas como libre actividad privada, sino que interviniera en el proceso económico, pero contemplado desde el punto de vista del empresario. Lo anterior llevó a que la economía invadiera también la vida política, creándose al lado del derecho económico un derecho obrero, que se origina en la clase trabajadora y se impone al Estado como una medida de protección del débil frente al poderoso. Ambos estatutos jurídicos se inspiran en propósitos diversos, que en ocasiones parecen contradictorios y entran en lucha, pero cada vez más va penetrando el uno en el otro, creando una nueva relación que no puede ser atribuida ni al derecho público ni al

\footnotetext{
54 Radbruch, Gustav. Introducción a la Ciencia del Derecho. Traducción de Luis Recasens Siches. Madrid, España: Imprenta Helénica, 1930 , p. 78 y ss.

55 Duguit, León. Traité de Droit Constitutionnel. Tomo I. -2. ed.-. París, Francia: Ancienne Librarie Fontemoin Cie. Edit, 1921, p. 522.
} 
derecho privado, sino que representa un derecho nuevo, de un tercer tipo, un derecho social, que nace de la fusión de determinados aspectos propios de los dos estatutos mencionados.

Pero lo que no puede negarse es que el Derecho del Trabajo nace frente a la incapacidad o insuficiencia del Derecho Civil para dar explicación satisfactoria a muchas de sus instituciones, lo que le ha significado una eterna lucha por la defensa de su autonomía, independencia o particularidad frente a la disciplina privada.

La idea en sí no es novedosa. Es así como Arias indica que la incorporación de una teoría general del Derecho del Trabajo a la teoría del derecho común implica, necesariamente, la aplicación de las normas de la igualdad formal lo que, en materia de responsabilidad, se ve agravado por el hecho de que el sector patronal queda en posición de escamotear sus obligaciones, mediante el argumento de que el Derecho del Trabajo es un derecho "especial, transaccional y tarifado"

El autor sintetiza los elementos que, a su juicio, deben presidir la construcción de una teoría crítica del Derecho del Trabajo en los siguientes: a) una metodología que parta de lo real, para llegar a la formación de un aparato conceptual que permita entender la realidad; b) la construcción de un discurso jurídico laboral, consistente en los principios jurídicos constitucionales; y c) considerar que el discurso jurídico opera sobre relaciones socialmente concretas que necesitan, a su vez, ser comprendidas ${ }^{57}$.

\section{FUNDAMENTO LEGAL DE LA APLICACIÓN DEL DERECHO CIVIL EN EL DERECHO DEL TRABAJO}

La aplicación directa de normas e instituciones propias del Derecho Civil en la regulación de relaciones laborales es una cuestión recurrente y cuya legitimidad resulta, en la actualidad, unánimemente aceptada. Es evidente que cuando tal cuestión ocurre por mandato expreso del Código del Trabajo o de la legislación laboral especial resulta absolutamente comprensible. Pero ello no se limita a estos casos, sino a todas aquellas materias no reguladas en la ley y en que se hace indispensable recurrir a los conceptos del considerado derecho común, particularmente en lo que dice relación con la regulación de los contratos e instituciones afines.

Sin embargo, es procedente hacer mención al artículo $4^{\circ}$ del Código Civil, que dispone que "Las disposiciones contenidas en los Códigos de Comercio, de Minería, del Ejército, y Armada, y demás especiales, se aplicarán con preferencia a las de este Código". Los alcances de esta norma no son compartidos unánimemente por la doctrina nacional.

Alessandri, Somarriva y Vodanovic, caracterizando al Derecho Civil como derecho privado general y común, explicaron que es general porque "todas las relaciones jurídicas privadas de los hombres que no están disciplinadas por otra rama especial o autónoma del derecho, son regidas por el Derecho civil". Es común, en el decir de los autores, "porque sus principios y normas generales suplen las lagunas o vacíos de las demás ramas del derecho privado cuando ellas no aparecen inspiradas por principios singulares que contradigan a los del común"58. Para estos eminentes tratadistas, el Derecho Civil:

\footnotetext{
56 Arias Gilbert, Enrique, op. cit. (n. 27), p. 6.

57 Ibid., p. 7.

58 Alessandri, Arturo; Somarriva, Manuel; Vodanovic, Antonio. Tratado de Derecho Civil. Partes Preliminar y General. Tomo I. -6º Ed.-. Santiago, Chile: Editorial Jurídica de Chile, 1998, p. 84.
} 
Gabriela Lanata Fuenzalida/La aplicación del Derecho Civil en el Derecho del Trabajo

“Tiene el carácter supletorio de los derechos especiales, mediata o inmediatamente, cuando éstos carecen de preceptos adecuados sobre un asunto o materia propios de su competencia como se ha subrayado, este carácter supletorio erige al Derecho civil en el representante de la unidad del Derecho Privado que, en su diverso fraccionamiento (derecho comercial, derecho de minas, derecho del trabajo, derecho industrial) adquiere cierta cohesión unitaria a través de aquél"59.

Corral estima que el artículo $4^{\circ}$, en análisis, es el llamado a llenar los vacíos de cualquier otra legislación, norma que "traduce un principio más general que inspira todo nuestro ordenamiento jurídico y le confiere una estructura (siquiera aspiracionalmente) racional, orgánica y coherente. No habría realmente ordenamiento si las disposiciones normativas operaran como islas independientes sin conexión algunas entre sí". Y agrega que "los distintos cuerpos legales no operan solos, aislados unos de otros, sino sobre la base de reglas, de principios, que ya forman parte del acervo común de todo operador jurídico. Esta es la función del llamado Derecho común que en materia de derecho privado está representado por el Código Civil"60.

En la doctrina nacional, Vergara Blanco al negar la posibilidad de aplicación supletoria del Derecho Civil y, concretamente, del Código Civil en el Derecho del Trabajo, concluyó que los principios del Derecho Laboral son antitéticos con los del Derecho Civil "de cuyas normas sobre prestación de servicios personales huyó despavorido el legislador del trabajo subordinado y protegido" ${ }^{61}$. Para este autor, la ausencia de una norma supletoria en el Código del Trabajo implica el rechazo a la supletoriedad y lo dispuesto en el artículo $1^{\circ}$ del Código del Trabajo, deja en claro su autonomía.

Vergara niega que tal disposición signifique una aplicación supletoria amplia a toda otra disciplina ${ }^{62}$. Sostiene el autor que en esta norma no se ha hecho aplicación de una técnica de supletoriedad, sino que sólo se limita a consagrar el principio de la especialidad, pero su aplicación preferente implica lo contrario a la aplicación supletoria, con lo que se viene a excluir, a reafirmar la autonomía normativa y disciplinaria. El autor va más allá y postula la negación del Derecho Civil como supuesto centro del universo jurídico, pues, señala, no existe un "derecho común" general para el ordenamiento jurídico y, en todo caso, ese papel no le correspondería al Código Civil ${ }^{63}$, aun cuando acepta tal aplicación como coherente y racional respecto de disciplinas de naturaleza privada, pero no de aquellas que tienen el carácter de públicas. Para Vergara la clasificación de las disciplinas jurídicas en públicas o privadas obedece al contenido esencial de cada una de ellas y a la clasificación de las mismas que haga el jurista ${ }^{64}$. En este sentido, califica al derecho laboral de privado, por ser su caracterización más acusada "la existencia de una relación entre privados o particulares" ${ }^{65}$, remarcando la inexistencia de potestades públicas en las relaciones jurídicas que en ella se desenvuelven. Con ello, podríamos llegar a concluir que no repugna al autor la aplicación supletoria del Derecho Civil en el Derecho del Trabajo, en virtud de la norma contenida en el artículo $4^{\circ}$ del Código Civil.

\footnotetext{
Ibid., p. 60.

Corral Talciani, Hernán. Lecciones de responsabilidad extracontractual. Santiago, Chile: Editorial Jurídica de Chile, 2003 , p. 31.

Vergara Blanco, Alejandro. El Derecho Administrativo como sistema autónomo. El mito del Código Civil como "Derecho Común". Santiago, Chile: Editorial AbeledoPerrot, Chile, 2010, p. 50.

Ibid., p. 52.

Ibid., p. 67.

Ibid., p. 107.

Ibid., p. 108.
} 
Pero, se quiera o no, el punto de partida en este aspecto lo determina el artículo $4^{\circ}$ del Código Civil, disposición ya transcrita y a cuyo respecto cabe advertir que la omisión de toda referencia al Código del Trabajo se debe al simple hecho de que el Código Civil data de 1855 y el primer Código del Trabajo solamente de 1931. En otras palabras, hasta principios del siglo XIX las relaciones laborales que pudieran existir eran reguladas las normas contractuales contenidas en el Código Civil.

La norma transcrita constituye el fundamento positivo de la aplicación supletoria del Derecho Civil en las relaciones propias del Derecho del Trabajo, aun cuando no ha provocado mayor detención ni en la doctrina ni en la jurisprudencia, las que se limitan a recurrir a la aplicación de las normas civiles, casi porque existen o por una generalizada suposición de que ello constituye única respuesta necesaria a la falta de regulación de ciertas instituciones de carácter general, en el sentido de que encuentran aplicación en diferentes disciplinas jurídicas, aun cuando su desarrollo sea propio del Derecho Civil, aun cuando en casos aislados se ha justificado tal aplicación en el referido artículo $4^{\circ}$, aun cuando sin mayores profundizaciones al respecto ${ }^{66}$.

\section{LA SITUACIÓN CONCRETA EN CHILE}

En la realidad chilena la materia se ha esbozado de la siguiente forma: por un lado, existen situaciones en que se ha hecho una remisión expresa a ciertas instituciones a normas específicas del Derecho Civil, caso en los cuales su aplicación se efectúa por mandato del propio legislador laboral y no por una simple supletoriedad. En otras, la ley laboral se remite a instituciones civiles, sin mayor detalle ni regulación. Existen algunas, aún, en las cuales se trata efectivamente de vacíos, en los cuales las normas civiles vienen a llenarlos, proporcionando soluciones que pueden considerarse adecuadas. En cualquier caso, cuando los tribunales de justicia aplican las normas civiles deben necesariamente efectuar una "adaptación", derivada de las particularidades de la disciplina laboral ${ }^{67}$. Esta situación se constata con mayor claridad en algunos casos en que han sido, precisamente, los tribunales los que han recurrido a las normas civiles, por considerarlas más protectoras aún que las propias normas contempladas por el derecho laboral.

Digna de destacar resulta la ya casi emblemática situación de la indemnización del que se ha denominado lucro cesante por incumplimiento de un contrato por obra o servicios o a plazo fijo, en que la protección del Código del Trabajo puede llegar a resultar más perjudicial que aquella conferida por el Código Civil y a cuyo respecto los tribunales no han dudado en aplicar aquella norma que resulta más favorable al trabajador, siguiendo un criterio institucional, aun cuando sin hacer mención expresa a principio alguno en tal sentido.

Desde hace ya algunos años, la Corte Suprema ${ }^{68}$ sentó jurisprudencia en el sentido que, si bien el Código del Trabajo no prevé expresamente la indemnización por lucro cesante en estos casos, sin embargo, el Derecho del Trabajo no puede considerarse aislado del ordenamiento jurídico en general, el cual ha de estimarse como la base de la acción deducida por los trabajadores, es decir, el conjunto de normas que regulan el desenvolvimiento en sociedad. En otros términos, se

\footnotetext{
66 La Corte Suprema, en un fallo del 17 de noviembre de 2009, dictado en una causa laboral, rol № 7.021-09, refiriéndose a la procedencia de la indemnización por lucro cesante frente a la terminación anticipada de un contrato por obra, sostuvo que resulta aplicable el artículo 1556 del Código Civil, conforme a lo dispuesto en el artículo $4^{\circ}$ de ese mismo Código, "en la medida en que éste hace regir las leyes especiales con preferencia, pero, en ningún caso, con exclusión de sus normas".

67 Mangarelli, Cristina, op. cit. (n. 17), p. 18.

68 Rol 281-2006.
} 
Gabriela Lanata Fuenzalida/La aplicación del Derecho Civil en el Derecho del Trabajo

basa en la concepción jurídica recogida por las leyes y, concretamente, en el derecho que propugna que una parte tiene que ser indemnizada en el evento que su contraria no dé cumplimiento a lo pactado, por cuanto ha dejado de ganar aquello que, como contratante cumplidor, tenía derecho a exigir y percibir. Se reconoce que el origen de la indemnización se encuentra en los principios generales del derecho y, en especial, en la idea básica de que, frente al incumplimiento del contrato por parte del empleador en orden a otorgar el trabajo convenido y pagar las correspondientes remuneraciones hasta el vencimiento de la obra de acuerdo a las estipulaciones pactadas libremente, cabe concluir que el empleador se ha transformado en un contratante no diligente y, por ende, el trabajador tienen el derecho a reclamar la contraprestación que le hubiere sido legítimo percibir, de no haberse producido el incumplimiento. Es decir, goza de un derecho cuya fuente se encuentra en la ley laboral, cual es, las remuneraciones dejadas de percibir ilegítimamente, pues es de la esencia del contrato de naturaleza laboral, conforme a la definición contenida en el artículo $7^{\circ}$ del Código del Trabajo, el pago de la remuneración convenida, en la medida que, por su parte, el trabajador haya invertido su fuerza laboral en la actividad acordada. En el caso cierto, se agrega en el fallo, los actores no han prestado esos servicios con posterioridad al despido, pero esa omisión no les es imputable, sino que ha obedecido a la negligencia del empleador quien los ha desvinculado unilateralmente y de manera improcedente.

Evidentemente, no es exacto hablar de remuneraciones ni tampoco explica el fallo por qué no da aplicación estricta a la disposición del artículo 168 del Código del Trabajo que prevé expresamente esta situación y establece que, en tal caso, corresponde al empleador pagar la indemnización por años de servicio con el recargo respectivo y la sustitutiva del aviso previo.

La situación fue corroborada más recientemente, con la dictación de un fallo en unificación de jurisprudencia ${ }^{69}$, que reconoció la posibilidad enunciada y estableció que la correcta doctrina es aquella que confiere el derecho a indemnización al trabajador y, dando aplicación a las normas del Código Civil, se decidió que respecto de los demandantes cuyo contrato de trabajo por obra terminó por despido injustificado y anticipado de su empleador, procede el pago de la indemnización por lucro cesante equivalente al monto de las remuneraciones que debían percibir desde el despido al término de la obra, compartiendo en ese sentido íntegramente lo expresado en la sentencia de la instancia, en la que se afirma:

\begin{abstract}
"Si bien el Código del Trabajo no contempla expresamente esta indemnización, esta rama del derecho no puede considerarse aislada del resto del ordenamiento jurídico general, el cual reconoce el derecho que una parte tiene a ser indemnizada en el evento que la contraria no de cumplimiento a lo pactado, puesto que ha dejado de ganar aquello que como contratante cumplidor, tenía derecho a exigir y percibir, y que en la especie corresponde a las remuneraciones que las partes habían acordado por todos los meses que restan desde la época del despido hasta el vencimiento natural del contrato celebrado, esto es, en la fecha que se indicará. Concluir algo distinto dejaría a un trabajador en peor posición que cualquier otra persona que no detente esa calidad y a quien se le incumpla un contrato contractual civil, lo que pugna con los principios de protección del derecho laboral".
\end{abstract}

El fallo del tribunal de fondo se sustentó en lo dispuesto en los artículos 1556 y 1545 del Código Civil, estimándose que el derecho laboral no puede considerarse aislado de todo el ordenamiento jurídico, por lo que no se vulnerarían las normas relativa al despido injustificado,

69 Corte Suprema, rol 4259-2011, de 30 de enero de 2012. 
cuestión que sostenía el demandado en la contestación a la demanda, argumento que compartió la respectiva Corte de Apelaciones y que motivó se recurriera de unificación de jurisprudencia para ante la Corte Suprema.

Si bien el Máximo Tribunal hace referencia al principio protector, el fallo no llegó a hacer presente que, en realidad, la determinación de la procedencia de esa indemnización y de la aplicación de las normas contenidas en el Código Civil, no hacen sino aplicación de una manifestación de una manifestación concreta y puntual del principio protector, ya suficientemente desarrollado por la doctrina y, específicamente, de la determinación de la norma más favorable, inclinándose, al momento de determinar cuál es la norma más favorable, por seguir la teoría de la institución.

Se observa que la esencia misma de la regulación positiva laboral se respetó en la decisión de los tribunales, pero se advierte que ello no obedeció de manera clara y consciente a una determinación exacta de la naturaleza jurídica del Derecho del Trabajo, sino que simplemente se observó que la solución contractual consagrada en el Código Civil resultaba más beneficiosa para el trabajador.

Tampoco puede concluirse que este tipo de razonamiento sea el utilizado de manera uniforme por nuestros tribunales, sino que parece ser la excepción, pues en otros análisis jurídicos se ha aceptado sin más

Otro ejemplo en que se ha observado la noción clara del verdadero sentido del Derecho del Trabajo ha sido en la que se ha denominado como la idea del holding de empresas y su relación con la disciplina, desarrollada también por la jurisprudencia.

El holding ha sido entendido por la jurisprudencia de la Corte Suprema como un conjunto de empresas relacionadas, las que en general presentan un patrimonio común o parte de éste es compartido. La intensidad de estas relaciones puede darse en mayor o menor medida, pero conservan su independencia jurídica. Claro está, que la traba legal se encuentra en la exigencia del artículo 3 del Código del Trabajo en orden a que la empresa deba estar dotada de una individualidad legal determinada.

"Este tipo de relaciones, en gran cantidad de ocasiones, son tan estrechas que la doctrina, haciendo una comparación con el Derecho de Familia, les ha asignado vínculos parentales, otorgándole el carácter de sociedad madre a aquella que ejerce el dominio sobre el grupo, y de hermanas, a aquellas que aún con personalidades jurídicas propias se encuentran bajo la égida de la anterior. Otras veces, aun cuando el tipo de relaciones que se entablan no permite determinar la existencia de una sociedad dominante, en cambio, existe una confusión patrimonial tan intensa, que las mismas actúan conformando una unidad económica"70.

Como afirma Hierrezuelo, estos fenómenos "que producen una verdadera telaraña por las interconexiones que se entablan entre las distintas sociedades, repercuten sin hesitación, en el Derecho del Trabajo, pues el trabajador se encuentra muchas veces en el centro de ese circuito interempresarial, sin saber con certeza quien le paga, quien lo dirige ni a quién debe obedecer"71.

\footnotetext{
70 Hierrezuelo, Ricardo D. y Núnez, Pedro F. Responsabilidad solidaria en el contrato de trabajo. Primer libro de la colección de la Sociedad Argentina de Derecho Laboral, Director Julio Armando Grisolía. Buenoas Aires, Argentina: Hammurabi, 2003 , pp. 51 y 52. Citado por Hierrezuelo, Ricardo D. y Núnez, Pedro F., op. cit. (n. 28), p. 215.

71 Ibid., p. 251.
} 
Gabriela Lanata Fuenzalida/La aplicación del Derecho Civil en el Derecho del Trabajo

En Chile no existe una norma análoga a aquella contemplada en el artículo 31 de la Ley de Contrato de Trabajo argentina ${ }^{72}$, lo que no significa que en el desarrollo de gran parte de actividades se recurra a grupos económicos, habiendo sido la jurisprudencia judicial, al igual como ha ocurrido en otros países, la que se ha encargado de buscar las formas de dar protección a los trabajadores involucrados, advirtiéndose en estos aspectos también la insuficiencia de las normas de derecho común, al dar preeminencia a la individualidad jurídica de cada entidad comprometida y a la ausencia de responsabilidad solidaria no contemplada en la ley. Se ha recurrido a desarrollar y aplicar el principio de la primacía de la solidaridad, por sobre la rigidez jurídica de nuestros conceptos legales, buscando desentrañar la verdad de las situaciones, más allá de lo que indiquen los documentos que den cuenta de la voluntad de las partes.

Como señala Pollero ${ }^{73}$, no siempre resulta fácil determinar cuándo dos o más empresas constituyen un grupo económico, pero resulta de común ocurrencia la existencia de diversos tipos de sociedades, ya sean de la misma naturaleza o diferente, que se encuentran de tal modo relacionadas que su personal o parte de él trabaja simultáneamente para varias de ellas, o para todas, aunque figura en las nóminas de una sola. El problema, como se vislumbra fácilmente, se presenta cuando un trabajador desea hacer efectiva alguna prestación y no le resulta fácil la identificación del responsable del pago de la misma o, lo que es peor, cuando logra determinarlo se encuentra con la insolvencia de la misma. En la mayoría de los casos, por no decir en todos, no se ha perseguido la idea de fraude en la celebración de actos o realización de operaciones tendientes a alterar la personalidad jurídica, sino que se han preocupado, más bien, de restarle importancia a esa realidad, procurando evitar los efectos nocivos que esas actuaciones pueden producir en los derechos de los trabajadores.

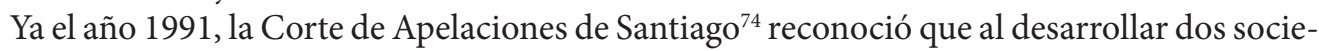
dades un solo giro, bajo una misma gerencia, constituían una sola empresa dado que ambas concurren al logro de un fin económico común, privilegiando de esta forma la actividad empresarial obviando la organización jurídica en más de una entidad.

Más adelante, la Corte Suprema, el 6 de junio de $2000^{75}$, rechazó el recurso de casación interpuesto en contra del fallo de la Corte de Apelaciones de Santiago, de 26 de abril de 1999, por el cual se había reconocido que la demandada constituía un holding con otras empresas relacionadas, por lo que quienes se desempeñaban como directores del mismo holding debían recibir una sola remuneración y no un sueldo de cada empresa que conformaban el conjunto, lo que aparecía, se dijo, más conforme con la realidad.

La Corte de Apelaciones de Santiago, en fallo de 9 de enero de $2001^{76}$ en un caso relativo a la Administradora de Inversiones y Supermercados Unimarc S.A., sostuvo que, atendido que los sucesivos cambios de empleador eran puramente formales en razón de la no discutida relación de propiedad de las empresas, cabía hacer lugar a la demanda indemnizatoria de un trabajador,

\footnotetext{
72 "Art. 31. Empresas subordinadas o relacionadas. Solidaridad.

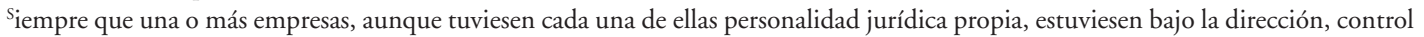
o administración de otras, o de tal modo relacionadas que constituyan un conjunto económico de carácter permanente, serán a los fines de las obligaciones contraídas por cada una de ellas con sus trabajadores y con los organismos de seguridad social, solidariamente responsables, cuando hayan mediado maniobras fraudulentas o conducción temeraria."

Pollero, Daniel Edgardo. "La responsabilidad solidaria de los integrantes de grupos económicos", en: Revista de Derecho Laboral, $\mathrm{n}^{\circ}$ 1, año 2011, p. 344, Buenos Aires, Argentina, Rubinzal-Culzoni Editores.

74 Corte de Apelaciones de Santiago, rol 307-1991.

75 Corte de Apelaciones de Santiago, rol 2198-1999.

76 Corte de Apelaciones de Santiago, rol 982-2000.
} 
obligación que hizo recaer en la empresa demandada, por haber sido ésta con quien se celebró el último de los contratos de trabajo, situación que fue reconocida por la Corte Suprema, en fallo de 17 de julio de $2001^{77}$.

Ya más adelante, la situación siguió delimitándose, estableciendo la Corte Suprema en un fallo de 13 de agosto de 2003, un concepto de holding y su influencia en las relaciones laborales. Un grupo de trabajadores demandó a tres sociedades de responsabilidad limitada, representadas por un mismo apoderado, y a una cuarta, representada por otra persona, todas de igual domicilio "a fin que conjunta y solidariamente sean condenadas al pago de las remuneraciones insolutas que se les adeudan, por los fundamentos que se consignan". Los actores fundamentaron la responsabilidad solidaria en el artículo 4 del Código del Trabajo, que es el que consagra el principio de la continuidad de la empresa, pero ninguna referencia efectúa a la existencia de solidaridad.

El tribunal de primer grado, en fallo de 2 de abril de 2001, estimó que los trabajadores se desempeñaban indistintamente para las tres primeras entidades, por lo que las condenó a pagar las remuneraciones adeudadas en forma solidaria, pero excluyó a la cuarta demandada, porque ninguno de los trabajadores se desempeñaba para esa sociedad al tiempo de la demanda.

La Corte de Apelaciones de Santiago, el 30 de agosto de $2002^{78}$, confirmó la sentencia de primer grado, pero revocó en cuanto estimó que cada una de las sociedades se ajustaba al concepto de empresa del artículo 3 del Código del Trabajo, al estar, cada una de ellas, dotada de una individualidad legal determinada, señalando en su consideración séptima que “...siendo de advertir que los demandantes no han siquiera invocado en su demanda que la constitución de dichas empresas haya tenido por objeto eludir el cumplimiento de obligaciones laborales por lo que su pretensión no puede entenderse enmarcada en la disposición del artículo 478 del Código del Trabajo". De esta forma, condenó a cada una de las sociedades al pago de las prestaciones indicadas en la sentencia de primer grado, pero debiendo responder únicamente de aquella deuda en relación a sus respectivos trabajadores, desestimándose la solidaridad, por no haberse establecido que las citadas empresas, configurasen un solo todo o hayan sido coligadas bajo una misma organización $\mathrm{y}$ con un giro único.

Sin embargo, la Corte Suprema, en sentencia de 13 de agosto de 2003 resolvió "Que el último requisito establecido en la norma citada, -refiriéndose al concepto de empresa del artículo tercero $^{79}$ - según lo ha resuelto esta Corte, no debe entenderse el atributo de la personalidad jurídica. Basta un ser jurídico". Y agregó en su consideración quinta:

"Que es un derecho del ser humano producir y tal derecho emana de su naturaleza. La ley sólo tiene que reconocerlo y ampararlo. Tal facultad del ser humano ha ido variando, en cuanto a su forma de ejercicio y ha ido adoptando evolucionados y diferentes modelos. Uno de ellos es el denominado "holding" o conjunto de empresas relacionadas, las que en general presentan un patrimonio común o parte de éste es compartido. Atento a tales cambios, en la especie, ha de hacerse primar el principio de la realidad, esto es, la verdad o autenticidad en las relaciones laborales, aquello que son y no lo que las partes han querido que sean".

\footnotetext{
7 Corte Suprema, rol 858-2001, en: Gaceta Jurídica N 253, p.199.

78 Corte de Apelaciones de Santiago, rol 4.570-2001.

79 El artículo $3^{\circ}$ del Código del Trabajo, dispone que "Para los efectos de la legislación laboral y de seguridad social, se entiende por empresa toda organización de medios personales, materiales e inmateriales, ordenados bajo una dirección, para el logro de fines económicos, sociales, culturales o benéficos, dotada de una individualidad legal determinada”.
} 
Y todavía agregó:

"Que en la confrontación de los hechos de esta causa con las normas previstas en los artículos $3^{\circ}$ y $4^{\circ}$ del Código del Trabajo en examen y lo razonado, se evidencia que en el caso de autos se está en presencia de un "holding". En efecto, ya está dicho que las empresas individualizadas, aparte de tener la calidad de relacionadas, se ordenan bajo una misma dirección, lo que las hace actuar ante los trabajadores y terceros como unidad económica". $\operatorname{grado}^{80}$

De esta forma, restableció la solidaridad que había determinado la sentencia de primer

Como se puede observar, la situación varió respecto de los fallos anteriores, al condenarse a todas las sociedades demandadas en forma solidaria, lo que en sí constituye una novedad, dado que según el artículo 1511 del Código Civil, la solidaridad puede tener por fuente la convención, el testamento o la ley, pero no una sentencia judicial. Obedecen estos planteamientos a la aplicación del principio de la primacía de la realidad, dando preeminencia a lo real por sobre los formal. Por otra parte, una empresa no puede aprovecharse de los beneficios que puede suponer la creación de un grupo y no responder de los perjuicios que se puedan ocasionar ${ }^{81}$.

La tendencia jurisprudencial siguió desarrollándose en este mismo sentido, pareciendo seguir el criterio del desarrollo del giro del negocio o actividad económica emprendida, independientemente del número de entidades jurídicas que se requiera para el desarrollo del mismo.

Así se sentenció también por la Corte de Apelaciones de Concepción, que en fallo de 9 de mayo de $2007^{82}$, en que frente a la demanda de las cajeras de una multitienda, que figuraban contratadas por un intermediario inubicable, indicó que no podía sino concluirse que ambas entidades, Almacenes París Comercial S.A. y Administradora y Comercial Bio-Bio Ltda., no eran más que organizaciones jurídicas que permitían la realización de una misma actividad productiva, esto es, la comercialización de productos, pudiendo considerarse para todos los efectos laborales y previsionales como una sola empresa, en el sentido que le confiere el artículo 3 del Código del Trabajo. Consideró el tribunal que debe recordarse que la relación que une a las partes contratantes en un contrato de trabajo, no es igual a una relación contractual regulada por el Derecho Civil. El Derecho del Trabajo nace precisamente frente a la insuficiencia del derecho contractual civil, para dar respuesta justa a los requerimientos jurídicos de una de las partes involucradas, especialmente por aplicación de los principios de la autonomía de la voluntad y de la premisa básica de la igualdad de los contratantes. Las partes involucradas en un contrato de trabajo no están en un plano de igualdad; por el contrario, se trata del reconocimiento de la diferencia que existe entre ellas y de buscar la debida protección a la parte débil de la misma, esto es, del trabajador. El Derecho del Trabajo ha reconocido una serie de principios e instituciones ya fuertemente afianzadas en la vida laboral del país, tales como la irrenunciabilidad de los derechos que la ley laboral les reconoce, la continuidad de la empresa, la presunción de representación del empleador y el principio de la primacía de la realidad. En este contexto, uno de los aspectos que debía considerarse, afirmó, es que la relación laboral se desarrollaba en el marco de una unidad productiva denominada empresa, que puede presentar diferentes formas jurídicas, ya sea en forma paralela o sucesiva, que son las que

\footnotetext{
80 Gaceta Jurídica $\mathrm{N}^{\circ} 278$, p. 224.

81 García Vicente, Jaume. Responsabilidad solidaria y el levantamiento del velo en la jurisdicción social. Barcelona, España: J.M. Bosch Editor, 2003, p. 155.

82 Corte de Apelaciones de Concepción, rol 3536-2006.
} 
le permitirán desarrollar su labor productiva de acuerdo a las sofisticadas necesidades de la vida moderna. Sin embargo, la satisfacción de tal necesidad económica en caso alguno puede llegar a significar un perjuicio para los trabajadores, dado que la relación laboral se verifica entre un trabajador y una organización empresarial, considerándose tal, como lo indica el artículo 3 del Código del Trabajo, a toda organización de medios personales, materiales e inmateriales, ordenados bajo una dirección, para el logro de fines económicos, sociales, culturales o benéficos, dotada de una individualidad legal determinada. En esta organización llamada empresa se inserta también el trabajo personal, como parte del proceso productivo destinado a producir bienes o prestar servicios, aprovechándose esta organización de los servicios del trabajador, quien obtiene a cambio, una determinada retribución compuesta esencial y principalmente por su remuneración y otras prestaciones reconocidas por la ley. Así entonces, cuando la organización jurídica de la que se ha dotado a la empresa no resulta clara o aparecen distintas individualidades legales, como ocurría en la especie, es menester entrar a determinar, amparados por el principio de la primacía de la realidad, dónde se encuentra realmente esa organización de medios materiales e inmateriales llamada empresa, resultando lícitos todos estos cambios, que bien pueden obedecer, como se señaló a necesidades inherentes a la explotación del giro productivo, pero sin que puedan significar en modo alguno, se reiteró, una vulneración a los derechos de los trabajadores.

Así entonces, en Chile han sido los tribunales de justicia quienes han superado, en cierta forma, la rigidez del concepto de empresa que contempla nuestra legislación, haciendo primar la protección de los trabajadores frente a las modificaciones o alteraciones que puede sufrir la personalidad jurídica de las entidades comprometidas en el desarrollo del giro que permite la actividad económica en la cual se inserta también la parte trabajadora, recurriendo al principio de la primacía de la realidad, para determinar la existencia o no de una unidad económica, haciendo caso omiso a la existencia de más de una entidad económica ${ }^{83}$. Lo interesante es que se pone en duda la pertinencia de la aplicación de conceptos netamente civiles o comerciales a las entidades empleadoras, alterando las concepciones tradicionales con el fin de adecuarlas a las necesidades generadas en los lugares de trabajo.

En todo caso, debe aclararse que la situación se vio alterada con la nueva regulación al trabajo en régimen de subcontratación e, incluso, al reconocimiento de la legitimidad del suministro de trabajadores, incorporado al Código del Trabajo con la dictación de la ley $\mathrm{N}^{\circ} 20.123$, en que se establece de forma legal la responsabilidad solidaria en determinadas situaciones. Esta normativa insistió, una vez más, en buscar soluciones en la órbita del llamado derecho común, dictaminando que la relación entre la denominada empresa principal y contratista emana de un contrato de naturaleza civil o comercial ${ }^{84}$, sin llegar a considerar que de lo que se trataba, al fin y al cabo, era de reconocer una forma nueva de producción y que la protección laboral debía ser dirigida hacia allá, como una cuestión propia de la esencia misma de la disciplina.

\section{CONCLUSIONES}

Como se observa, no existe claridad en cuanto a cuál es el exacto rol que juega el Derecho Civil en el Derecho del Trabajo. Sin embargo, la falta de exposición formal de una teoría general

\footnotetext{
83 Etala, Carlos Alberto. Interpretación y aplicación de las normas laborales. Buenos Aires, Argentina: Editorial Astrea, 2004, p.144.

84 Ello ha tenido consecuencias importantes, tales como la aplicación del artículo 22 de la Ley sobre Efecto Retroactivo de las Leyes y la determinación de la competencia de los tribunales, cuando se busca hacer efectiva la responsabilidad de la empresa principal establecida en los artículos 183-E del Código del trabajo, en relación con el artículo 66 bis de la ley $\mathrm{N}^{\circ} 16.744$.
} 
Gabriela Lanata Fuenzalida/La aplicación del Derecho Civil en el Derecho del Trabajo

no obsta a su autonomía, lo que no excluye la necesidad de recurrir a conceptos generales insertos en el Derecho Civil y que pueden constituir un aporte en el logro de la protección del trabajador. Esta afirmación, no obsta a la aceptación de las falencias que aún se constatan en la legislación chilena, en la cual podemos afirmar que la principal institución exclusiva del Derecho del Trabajo, cual es, el llamado contrato colectivo, simplemente, no ha sido reconocido como tal y lo que así se ha denominado está lejos de asemejarse a lo que, en esencia, la constituye.

No obstante las aprehensiones que puedan generar las ideas planteadas es una realidad indiscutible que las normas civiles en muchos aspectos y, especialmente en materia de responsabilidad, se han elevado como la respuesta desesperada- y a veces desconocida- frente a la insuficiencia de los regímenes laborales que confieren protección a los trabajadores tanto durante su vida activa como pasiva, transformándose la empresa o entidad empleadora, quienquiera que ésta sea, en la real responsable de la obligación de resarcir los perjuicios que algún infortunio ocasione al trabajador. El profesor Ramón Domínguez destaca la tendencia de suponer que toda reparación del daño queda comprendida dentro de la noción de responsabilidad civil, lo que no es efectivo, dado que los diversos sistemas de seguridad social pretenden el mismo objeto, pero con diversa cobertura y distinto fundamento, aun cuando el autor no desconoce la influencia que ésta ha tenido en la evolución actual de la responsabilidad civil ${ }^{85}$.

Se destaca la constatación de aquellos aspectos en que la justificación generalmente aceptada del nacimiento del Derecho del Trabajo, carece de verdadera significación, toda vez que la estricta aplicación de las normas laborales resulta menos beneficiosa de lo que habría sido la regulación por el Derecho Civil. Tales afirmaciones, sin embargo, están lejos de significar una defensa al desaparecimiento del amparo conferido a trabajadores por un derecho especial, con características propias que, de una u otra forma, resultan inexplicables por otras ramas del Derecho.

Así entonces, resulta válido plantearse en Chile lo que ya hizo Lyon-Caen ${ }^{86}$ en 1974, que reconoció que "El momento parece propicio para determinar si los conceptos del Derecho Civil, por mucho tiempo necesarios, no falsean hoy el desarrollo del Derecho del Trabajo, prohibiéndole tomar conciencia de sus propias necesidades". Y agregaba que "es oportuno interrogarse sobre el sentido de la legitimidad del uso de "normas" del Derecho Civil allí donde su dirección corre el riesgo de impugnarse; sobre todo allí donde su intervención perturba los efectos de una ley de progreso social" 87 .

El derecho positivo chileno parece haber obviado la cuestión reseñada, no porque se estime superada o solucionada sino, simplemente, porque no ha sido considerada, lo que ha llevado a indudables problemas prácticos que obligan a preguntarse si no será necesaria, como indicó LyonCaen, una elaboración legislativa que conduzca a la redacción de una Teoría General de Derecho del Trabajo, llamada a aclarar ciertos conceptos fundamentales, de manera independiente a la forma en que se ha hecho hasta ahora, en que se ha forzado la aplicación del derecho común a situaciones que, muchas veces, no contribuyen a cooperar en la solución del problema social, que es el que fundamenta siempre la dictación de las normas laborales. No se trata de eliminar toda aplicación de las normas de derecho común, sino de establecer principios y teorías básicas que permitan el claro discernimiento en los límites de esa aplicación.

\footnotetext{
85 Domínguez Águila, Ramón. "Responsabilidad Civil y Seguridad Social”. En: Universidad De Los Andes. La responsabilidad por accidentes del trabajo. Cuadernos de Extensión Jurídica, N 10, año 2005, p. 23.

86 LyOn-CaEN, G., op. cit. (n. 45).

87 Ibid., p. 330.
} 